IOSR Journal of Pharmacy

ISSN: 2250-3013, www.iosrphr.org

||| Volume 2 Issue 4 ||| July-August 2012 ||| PP.01-04

\title{
Frequency of IYC feeding practices among tribal children of Srikakulam District
}

\author{
Lakshmi $\mathrm{G}^{1}$ and Sambasiva Rao $\mathrm{R}^{2}$ \\ ${ }^{1}$ Senior Research fellow, Department of Anthropology, Andhra University, Visakhapatnam-530003. \\ ${ }^{2}$ Professor, Department of Anthropology, Andhra University, Visakhapatnam-530003.
}

\begin{abstract}
Feeding practices play a pivotal role in determining optimal development of infants. Poor breast feeding and infant feeding practices have adverse consequences for the health and nutritional status of children, which in turn has consequences on the mental and physical development of the child. A population based cross-sectional sample survey covering lactating mothers with a history of at least one child $(n=600)$ was carried out in the tribes of Srikakulam District, Andhra Pradesh. Interviews were conducted using a prepiloted structured questionnaire to inquire about breast feeding practices followed by the tribal mothers. The association of independent variables with breast feeding practices were examined by using statistical methods. The mean number of breast feeding episodes is 9.56 times among the neonates. During the night time, frequency of breast feeding is markedly less and is also gradually decreases as the age of the child increases. The frequency of breast feeding is more among the young children than the older children. The gap between the two episodes of breast feeding is less among the younger children than the older children.
\end{abstract}

Keywords—Breast feeding, neonates, nutritional status.

\section{INTRODUCTION}

The relationship between a mother and child is extremely important, especially with regard to breastfeeding habits. Breast feeding is an unequalled way of providing ideal food for the healthy growth and development of infants; it is also an integral part of the reproductive process with important implications for the health of mothers. As a global public health recommendation, infants should be exclusively breastfed for the first six months of life to achieve optimal growth, development and health (WHO, 2002). Breast feeding is the best way to satisfy the nutritional and psychological needs of the baby. Infants and young children need to be fed 5-6 times a day in addition to breast feeding. It must be remembered that inadequate feeding of infants and young children during the first two years is the main cause of malnutrition (Ministry of human resource development, 2004). Babies have a sucking reflex that enables them to suck and swallow milk. With some exceptions, human breast milk is the best source of nourishment for human infants. However, some scholars disagree on how long to breastfeed to gain the greatest benefit and how much more risk is involved in using artificial formulas instead of breast milk (Agostoni and Haschke, 2003).

\section{MATERIALS AND METHODS}

The study was conducted among Savara, Jatapu, Gadaba and Bagatha scheduled tribe of Srikakulam District. For the present study, 600 lactating mothers aged between 15-49 years who had at least one child and had breast feeding the last child within two years from the date of data collection were selected at random. Using pre-tested, semi-structured, and self administered questionnaire, information was obtained from the study respondents, in respect of breast feeding practices, the frequency of feeding episodes were also discussed. Data obtained were collated and analysis performed using SPSS-11 software.

\section{OBSERVAIONS}

The frequency of breast feeding to the children during day and night time was assessed according to the age of the child (Table-1\&2). The mean number of breast feeding episodes is calculated and are found to be decreased from the neonatal state to the childhood. The mean number of breast feeding episodes is $9.56 \pm 3.43$ times among the neonates i.e. within one month of age. In the second month the mean number of breast feeding episodes is 6.67 and is slowly decreasing to 3.00 times between $36^{\text {th }}$ and $48^{\text {th }}$ months at day time. During the night time frequency of breast feeding is markedly less i.e. among the neonates the mean number of breast feeding episodes is 6.00 times and is also gradually decreases as the age of the child increases to a maximum of 3.12 times at 24-36 months. 
During day time the average interval between the breast feeding episodes among the infants aged less than 5 months is $1-2$ hours; from $6^{\text {th }}-12^{\text {th }}$ month, the gap between two episodes increased to 2-3 hours. After 12 months upto the age of $48^{\text {th }}$ month the gap between two episodes of breast feeding at day time is 3-4 hours, whereas during night time two hours gap was maintained between breast feeding episodes among the infants who are less than 5 months old. The interval has increased upto 2.30 hours among the children aged between $6-8$ months. The gap between two episodes of breast feeding among the children between the age of $8^{\text {th }}$ and $36^{\text {th }}$ month is around 4 hours. The frequency of breast feeding is more among the young children than the older children. The gap between the two episodes of breast feeding is less among the younger children than the older children.

The study conducted by Swamy (2009) among the slum dwellers of Visakhapatnam the average suckling episodes during the first month are 17 times. The frequency of breast feeding decreases from 15 -10 times after first month and before $7^{\text {th }}$ month. As the infant was supplement with the serial food and is may be associated with the decline of milk secretion, which compel them to limit the suckling episodes from 8-9 times to 6-7 times by reaching $18^{\text {th }}$ month. The frequency during exclusive breast feeding stage among Parangi Poraja tribe ranges between 5-16 times per day. Among the infants who were initiated with complementary food the breast milk frequency drastically reduced, and is limited to 1-5 times per day (Pavani, 2009).

The average number of suckling episodes per day for children on exclusive breast-feeding was estimated to be 11 times in Indian infants, whereas in Maharashtra, West Bengal and Tamilnadu, the average suckling episodes per day among the children aged 0-3months was estimated to be 8.6, 9.5 and 5.4, respectively. Children more than 6 months age have an average suckling episodes 6 per day among slum children, While in Maharashtra, West Bengal and Tamilnadu it was reported to be 8.0, 8.6, 7.8 episodes per day, respectively. The corresponding average in the case of Andhra Pradesh (urban) was reported to be 6.1 episodes per day (WHO, 1981). Deepika (1991) revealed that an almost linear relationship between the frequency of suckling and duration of amenorrhoea for all age groups in tribals of Rajasthan. In general, mothers who breastfed their infants four times a day experienced an amenorrhoea period of 11.6 months, while those who breast-fed their infants 8.1 to 10 times a day had an amenorrhoea period extending upto an average of 14.5 months.

Similar to the present study, the mean frequency of feeding during the first 2 weeks of life in United states was $9.8 \pm 2.5 \mathrm{feeds} / 24 \mathrm{~h}$ and the mean duration of feeding was $162 \pm 50 \mathrm{~min} / 24 \mathrm{~h}$. Infants heavier at birth demanded significantly more feedings and nursed longer during the first 14 days of life. At one month the infants were nursing an average of $7.2 \pm 1.3$ times/24h and the mean duration of feeds was $158 \pm 63 \mathrm{~min} / 24 \mathrm{~h}$. Although the frequency of feeding during the first 14 days postpartum was significantly higher than at 1 month, the total duration of feeding in $24 \mathrm{~h}$ was similar. Daily milk intakes at 1 month ranged from 395 to $1011 \mathrm{ml}$ (mean $681 \pm 136 \mathrm{ml}$ ) and were not significantly correlated with either the frequency or duration of feedings (Manoel, 1982). In Kenya (Kenya Demographic and Health Survey, 2008-09) infants under 6 months of age were breast fed six or more times in 24 hours. Children are breastfed at an average of 7 times during the day and 5 times at night. 


\section{TABLES}

Table-1: Distribution of frequency of breast feeding during day time according to the age of the child

\begin{tabular}{|c|c|c|c|c|c|}
\hline \begin{tabular}{|l|l|}
$\begin{array}{l}\text { Age of the } \\
\text { (months) }\end{array}$ & \\
\end{tabular} & $\begin{array}{c}\text { childFrequency } \\
\text { BF }\end{array}$ & $\begin{array}{l}\text { of } \\
\begin{array}{l}\text { No.of } \\
\text { children }\end{array}\end{array}$ & Mean & SD & $\begin{array}{l}\text { Mean duration of feeding } \\
\text { (minutes) }\end{array}$ \\
\hline \multirow[t]{4}{*}{1} & $0-4$ & 1 & 9.56 & 3.43 & 75.31 \\
\hline & $4-8$ & - & & & \\
\hline & $8-12$ & 3 & & & \\
\hline & $12-15$ & 5 & & & \\
\hline \multirow[t]{4}{*}{2} & $0-4$ & - & 6.67 & 1.94 & 107.95 \\
\hline & $4-8$ & 6 & & & \\
\hline & $8-12$ & 12 & & & \\
\hline & $12-15$ & - & & & \\
\hline \multirow[t]{4}{*}{3} & $0-4$ & - & 7.06 & 1.75 & 101.98 \\
\hline & $4-8$ & 4 & & & \\
\hline & $8-12$ & 13 & & & \\
\hline & $12-15$ & - & & & \\
\hline \multirow[t]{4}{*}{4} & $0-4$ & - & 6.59 & 1.24 & 109.28 \\
\hline & $4-8$ & 16 & & & \\
\hline & $8-12$ & 13 & & & \\
\hline & $12-15$ & - & & & \\
\hline \multirow[t]{4}{*}{5} & $0-4$ & - & 6.40 & 2.31 & 112.50 \\
\hline & $4-8$ & 11 & & & \\
\hline & $8-12$ & 13 & & & \\
\hline & $12-15$ & 1 & & & \\
\hline \multirow[t]{4}{*}{6} & $0-4$ & - & 5.26 & 2.07 & 136.88 \\
\hline & $4-8$ & 19 & & & \\
\hline & $8-12$ & 4 & & & \\
\hline & $12-15$ & - & & & \\
\hline \multirow[t]{4}{*}{ 6-8 } & $0-4$ & 2 & 5.02 & 2.04 & 143.43 \\
\hline & $4-8$ & 40 & & & \\
\hline & $8-12$ & 10 & & & \\
\hline & $12-15$ & - & & & \\
\hline \multirow[t]{4}{*}{$8-12$} & $0-4$ & 40 & 4.52 & 1.95 & 159.28 \\
\hline & $4-8$ & 44 & & & \\
\hline & $8-12$ & - & & & \\
\hline & $12-15$ & - & & & \\
\hline \multirow[t]{4}{*}{$12-24$} & $0-4$ & 105 & 3.83 & 1.62 & 187.99 \\
\hline & $4-8$ & 173 & & & \\
\hline & $8-12$ & 1 & & & \\
\hline & $12-15$ & - & & & \\
\hline \multirow[t]{4}{*}{$24-36$} & $0-4$ & 28 & 3.19 & 0.85 & 225.71 \\
\hline & $4-8$ & 36 & & & \\
\hline & $8-12$ & - & & & \\
\hline & $12-15$ & - & & & \\
\hline \multirow[t]{4}{*}{$36-48$} & $0-4$ & 2 & 3.00 & 0.00 & 240.00 \\
\hline & $4-8$ & - & & & \\
\hline & $8-12$ & - & & & \\
\hline & $12-15$ & - & & & \\
\hline
\end{tabular}


Table-2: Distribution of frequency of breast feeding during night time according to the age of the child

\begin{tabular}{|c|c|c|c|c|c|}
\hline $\begin{array}{|lll|}\begin{array}{l}\text { Age of the child } \\
\text { (months) }\end{array} & & \\
\end{array}$ & $\begin{array}{l}\text { Frequency } \\
\text { BF }\end{array}$ & No. of children & Mean & SD & $\begin{array}{|lll|}\begin{array}{l}\text { Mean duration of } \\
\text { (minutes) }\end{array} & \text { feeding } \\
\end{array}$ \\
\hline \multirow[t]{2}{*}{1} & $0-4$ & 2 & 6.00 & 1.73 & 120.07 \\
\hline & $4-8$ & 7 & & & \\
\hline \multirow[t]{2}{*}{2} & $0-4$ & 1 & 6.78 & 0.94 & 106.19 \\
\hline & $4-8$ & 17 & & & \\
\hline \multirow[t]{2}{*}{3} & $0-4$ & 3 & 6.23 & 1.57 & 115.57 \\
\hline & $4-8$ & 14 & & & \\
\hline \multirow[t]{2}{*}{4} & $0-4$ & 3 & 5.79 & 2.02 & 124.35 \\
\hline & $4-8$ & 22 & & & \\
\hline \multirow[t]{2}{*}{5} & $0-4$ & 4 & 5.92 & 1.87 & 121.62 \\
\hline & $4-8$ & 9 & & & \\
\hline \multirow[t]{2}{*}{6} & $0-4$ & 10 & 4.70 & 1.55 & 153.19 \\
\hline & $4-8$ & 7 & & & \\
\hline \multirow[t]{2}{*}{ 6-8 } & $0-4$ & 26 & 4.69 & 1.67 & 153.52 \\
\hline & $4-8$ & 20 & & & \\
\hline \multirow[t]{2}{*}{$8-12$} & $0-4$ & 44 & 3.05 & 1.01 & 236.06 \\
\hline & $4-8$ & 9 & & & \\
\hline \multirow[t]{2}{*}{$12-24$} & $0-4$ & 117 & 3.26 & 1.01 & 220.86 \\
\hline & $4-8$ & 16 & & & \\
\hline \multirow[t]{2}{*}{$24-36$} & $0-4$ & 32 & 3.12 & 1.00 & 230.77 \\
\hline & $4-8$ & 1 & & & \\
\hline
\end{tabular}

\section{CONCLUSION}

In India, when children are very young (0-3 months), generally they are fed on demand. A high frequency of suckling was found among these tribes. The number of feeding required per day is more at the initial stage of the child, decreased throughout the first year. There should be proper encouragement to breast feed the baby.

\section{ACKNOWLEDGEMENTS}

An acknowledgement section may be presented after the conclusion, if desired.

\section{REFERENCES}

[1]. WHO. Infant and young child nutrition. Global strategy on infant and young child feeding. As formulated in the conclusions and recommendations of the expert consultation (Geneva, 28-30 March 2001) that completed the systematic review of the optimal duration of exclusive breastfeeding (see document A54/INF.DOC./4). See also resolution WHA54.2, 2002.

[2]. Ministry of Human Resource Development. National guidelines on infant and young child feeding. Department of women and child development, Food and Nutrition Board, Govt of India, 2004.

[3]. Agostoni C, Haschke F, Infant formulas, recent developments and new issues. Minerva Pediatr, 55(3).2003, p.195-207.

[4]. Swamy K.B., Infant Feeding practices among the slum dwellers of Visakhapatnam city, Andhra Pradesh, unpublished Thesis, Department of Anthropology, Andhra University, Visakhapatnam, Ph.D. 2009.

[5]. Pavani, Infant feeding practices among Pengu Porajas of Visakhapatnam District. Unpublished Dissertation, Department of Anthropology, Andhra University, Visakhapatnam, M.Sc,2009..

[6]. WHO, (1981). Contemporary Patterns of Breast-feeding, Report on the WHO Collaborative Study on Breast-feeding, Geneva

[7]. Deepika Puri, Breastfeeding among Tribals: An Aid to Fertility Control, The Journal of Family Welfare, 37(3).1991, p.55-60.

[8]. Manoel de Carvalho., Early Human Development, Volume 7, Issue 2, November, 1982, P. 155-163.

[9]. Kenya Demographic and Health Survey, (2008-09). Kenya National Bureau of Statistics and ICF Macro.: Key Findings. Calverton, Maryland, USA: KNBS and ICF Macro, 2008-2009. 